ABDIMAS: Jurnal Pengabdian Masyarakat Universitas Merdeka Malang
Vol.6(1) February 2021, 52-60
L-ISSN: 2721-138x e-ISSN: 2548-7159
Uttp://jurnal.unmer.ac.id/index.php/jpkm

\title{
Peningkatan Omset Penjualan Kelompok Pengrajin Keset melalui Online Marketing
}

\author{
Nathasa Pramudita Irianti ${ }^{1}$, Rizki Aprilia Dwi Susanti ${ }^{2}$, Odhitya Desta Triswidrananta ${ }^{3}$, \\ Elita Mega Selvia Wijaya ${ }^{1}$ \\ ${ }^{1}$ Departemen Pendidikan Matematika, 2Departemen Manajemen, Fakultas Ilmu Pendidikan, \\ Universitas Tribhuwana Tunggadewi \\ Jl. Telaga Warna, Malang, 65144, Indonesia \\ ${ }^{3}$ Departemen Manajemen Informatika, Teknologi Informasi, Politeknik Negeri Malang \\ Jl. Soekarno Hatta No.9, Malang, 65141, Indonesia
}

\begin{abstract}
ARTICLE INFO
Received: 2020-09-20

Revised: 2020-11-15

Accepted: 2021-01-20

Keywords:

Doorman craftsmanship group, Increased online marketing, Sales turnover

ABSTRACT

This program is carried out to increase the income of the "Mekar" women group in Sidoluhur Village, Lawang District, Malang. The "Mekar" women's group is a women's group of equality craftsmen made from patchwork. One of the obstacles they experienced was marketing constraints. Product marketing that has been carried out so far is only done conventionally by entrusting their products in several markets around the villages of Sidoluhur and Lawang. Therefore, an integrated marketing network effort is one of the efforts in increasing the sales turnover of this women's equality group. Efforts are made by providing assistance and training to this group to be activated in marketing products online. Online marketing starts by creating a social media account, selling in the market, then completing it by purchasing online marketing, and finally how to maximize sales on online marketing. Through assistance provided, "Mekar" women's groups that produce equality has been able to increase sales turnover by using online marketing. This increase in sales turnover reached 50\%. Understanding the marketing concept of "Mekar" women's groups which were originally only conventional has been developed for online marketing.
\end{abstract}

(C) 2021 Published by University of Merdeka Malang. This is an open access article distributed under the CC BY-SA 4.0 license (https://creativecommons.org/licenses/by-sa/4.0/)

How to cite: Irianti, N. P., Susanti, R. A. D., Triswidrananta, O. D., \& Wijaya, E. M. S. (2021). Peningkatan Omset Penjualan Kelompok Pengrajin Keset melalui Online Marketing. Abdimas: Jurnal Pengabdian Masyarakat Universitas Merdeka Malang, 6(1), 52-60. https://doi.org/10.26905/abdimas.v6i1.4819

\section{PENDAHULUAN}

Berkembangnya dunia usaha yang semakin maju, menuntut para pelaku usaha untuk semakin kreatif dalam menjalankan usahanya agar tetap mampu bertahan dalam persaingan pasar. Selain kualitas produk, pemasaran juga merupakan kunci kesuksesan dibalik sebuah usaha. Suyanto menyatakan bahwa pemasaran adalah fungsi bisnis yang mengidentifikasi kebutuhan konsumen yang harus dipuaskan oleh kegiatan manusia lainnya (Suyanto, 2007). Karena pada tahap inilah, produk dikomunikasikan kepada 
konsumen. Produk yang dikomunikasikan dengan baik tentu akan mendapatkan respon yang baik pula dan begitu sebaliknya. Di era modernisasi saat ini dimana teknologi berkembang dengan sangat pesat tidak dipungkiri juga telah merubah sistem pemsaran yang biasa dilakukan dengan cara konvensional beralih dengan cara digital.

Pemasaran digital atau digital marketing mulai populer sejalan dengan makin populernya penggunaan internet. Digital marketing menurut American Marketing Association (AMA) adalah aktivitas, institusi dan proses yang difasilitasi oleh teknologi digital dalam menciptakan, mengkomunikasikan, dan menyampaikan nilai-nilai kepada konsumen dan pihak yang berkepentingan lainnya (Kannan \& Li, 2017). Pemasaran media online pada dasarnya merupakan kegiatan pemasaran dengan menggunakan media internet. Internet sebagai bagian dari integrated marketing communication dapat dijadikan sebuah alat pemasaran yang sangat ideal. Penggunaaan teknologi internet dalam sistem penjualan online juga dirasakan manfaatnya oleh para konsumen (Widiana et al., 2012). Internet bisa menjangkau jutaan orang dalam sekali waktu dan juga bisa digunakan untuk mengejar target promosi dari sekelompok target pasar tertentu. Pada awalnya pemanfaatan internet sebagai media pemasaran hanya menggunakan halaman-halaman berformat HTML yang biasa diakses oleh pengguna internet, kemudia berkembang menjadi website yang menjadi "rumah kedua" atau kantor online bagi perusahaan yang sudah eksis untuk menampilkan jati diri perusahaan mereka. Saat ini kita telah merasakan perubahan yang sangat dnamis dan juga revolusioner dalam dunia marketing yaitu periklanan dan promosi. Perubahan-perubahan tersebut tentunya didorong oleh perkembangan teknologi yang semakin pesat dan juga perubahan gaya hidup masyarakat yang saat ini telah tergantung pada adanya internet. Internet telah merubah cara pelaku usaha dalam mendesain dan mengimplementasikan strategi bisnis mereka serta merubah pola komuniksi pemasaran mereka.

Hadirnya media sosial dan platform marketplace yang menjadi bagian dari perkemabngan teknologi, menjadi salah satu potensi untuk mengembangkan dunia usaha melalui online marketing yang awalnya hanya berupa website namun saat ini merambah semakin luas. Penelitian yang dilakukan oleh Piarna menunjukkan bahwa media sosial dapat dijadikan pelaku UMKM untuk dapat mengembangkan pemasarannya (Piarna \& Fathurohman, 2020). Media sosial memiliki potensi menghubungkan banyak orang dengan mudah. Media sosial saat ini tengah menjadi trend seolah menjadi bagian dari kebutuhan hidup seseorang. Kaplan dan Haenlein menyatakan bahwa media sosial merupakan sekelompok aplikasi berbasis internet yang dibangun berdasarkan kerangka pikiran ideologi dan teknologi dan memungkinkan terbentuknya pertukaran informasi dari pengguna internet (Kaplan \& Haenlein, 2010). Salah satu media sosial yang saat ini telah berkembang adalah Instagram (Indrayana et al.), Facebook, YouTube, dan WhatsApp (Harinie et al., 2020).

Selain media sosial, hadirnya platform marketplace merupakan ciri semakin berkembangnya bisnis pada era digital ini. Marketplace merupakan sebuah aplikasi online yang memfasilitasi proses jual beli dari berbagai toko. Marketplace menjadi paltform online marketing yang mudah dan murah karena para pelaku usaha tidak perlu mengeluarkan banyak biaya, seperti sewa tempat dan lainnya. Inilah salah satu alasan mengapa marketplace menjadi sarana jual beli yang saat ini banyak diminati oleh masyarakat. Beberapa marketplace yang banyak dimanfaatkan oleh pelaku usaha saat ini adalah Shopee (Hadi $\&$ Khairi, 2020), Tokopedia, dan Bukalapak (Rafiah, 2019). 
ABDIMAS: Jurnal Pengabdian Masyarakat Universitas Merdeka Malang Volume 6, No 1, February 2021: 52-60

Pada era transformasi digital saat ini, dimana dunia usaha juga telah berkembang sangat cepat. Pemasaran pun telah bergeser dari konvensional menjadi digital marketing haruslah menjadi peluang bagi para pelaku usaha UMKM agar lebih cepat dalam mengambangkan bisnis mereka. Kemudahan serta minimnya biaya dalam melakukan pemasaran online menjadi alternatif yang tepat dilakukan oleh pelaku usaha UMKM. Namun pada kenyataannya, banyak pelaku usaha kecil menengah yang saat ini belum menjamah online marketing karena adanya keterbatasan, selain keterbatasan jangkauan internet faktor minimnya pengetahuan dalam penggunaaan teknologi menjadi salah satu faktor utama yang dihadapi. Sehingga mereka kalah bersaing dengan para pelaku usaha sejenis yang lebih mampu memanfaatkan teknologi dalam menjalankan bisnis mereka.

Kabupaten Malang adalah kabupaten terluas kedua dengan populasi terbesar di Jawa Timur. Hal ini juga diikuti dengan permasalahan rendahnya kualitas sumber daya manusia yang menyebabkan melemahnya ekonomi masyarakat. Dari Badan Pusat Statistik tahun 2019, diketahui bahwa mayoritas pencari kerja di Kabupaten Malang adalah dari perempuan. Sebanyak 3.728 dari 4.825 pencari kerja adalah berjenis kelamin perempuan dan membuahkan persentase sekitar 77 persen (BPS Kabupaten Malang, 2019). Dalam upaya peningkatan kelompok wanita "Mekar" merupakan kelompok wanita pengrajin keset yang berada di Desa Sidoluhur, Kecamatan Lawang, Kabupaten Malang. Kelompok ini terdiri dari ibu rumah tangga dengan latar belakang kondisi ekonomi menengah kebawah. Kelompok ini sendiri mulai berdiri sejak 2017 yang dipelopori oleh Ibu Usta'ana. Ibu Usta'ana berhasil mengumpulkan beberapa ibu rumah tangga untuk menjadi anggotanya. Sejak Februari 2018 kelompok ini kemudian fokus untuk mengembangkan usaha kerajinan keset kain perca.
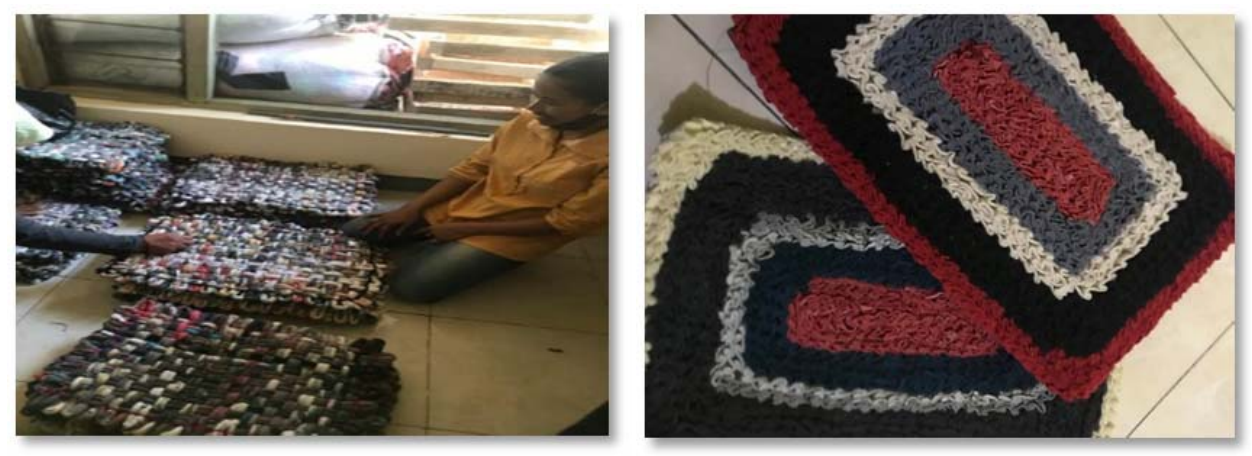

Gambar 1. Hasil produksi keset perca kelompok wanita Mekar

Seiring berjalannya waktu, usaha kerajinan keset kelompok ini mengalami penurunan. Letak geografis yang berada didaerah pegunungan membuat kelompok usaha ini semakin sulit untuk memasarkan produk mereka. Ditambah lagi, hampir sebagian besar dari anggota kelompok wanita ini kurang tanggap dengan teknologi, sehingga mereka hanya mengandalkan teknik pemasaran konvensional yaitu dengan cara menitipkan hasil kreasi mereka di toko atau menjual dari rumah ke rumah. Cara tersebut tentunya tidak efektif dan membuat produksi keset mereka banyak yang tidak terserap oleh pasar. Oleh karenanya dibutuhkan sebuah langkah nyata dalam membantu kelompok wanita "Mekar" ini dalam memasarkan keset percanya. 
Salah satu cara yang bisa dipakai dalam memasarkan suatu produk adalah dengan menggunakan online marketing. Online marketing ini sudah dilakukan oleh beberapa pelaku usaha, diantaranya adalah pelaku usaha di Desa Warnasari, Kecamatan Pangalengan, Kabupaten Bandung (Segarwati et al., 2020)

Berdasarkan permasalahan yang dihadapi oleh kelompok mitra ini, maka tim pengabdi bermaksud untuk melakukan kegiatan pelatihan dan pendampingan online marketing kepada kelompok pengusaha keset perca di Desa Sidoluhur, Kecamatan Lawang, Kabupaten Malang.

\section{METODE}

Program PKM Wirausaha Pengrajin Keset Perca ini dilaksanakan di Dusun Gunung Tumpuk, Desa Sidoluhur, Kecamatan Lawang, Kabupaten Malang. Dusun Gunung Tumpuk, terletak di Malang bagian Timur yang berjarak kurang lebih $23 \mathrm{~km}$ dari Pusat Kota Malang. 20 orang ibu-ibu yang mayoritas berprofesi sebagai Ibu Rumah Tangga (IRT) bergabung dalam suatu kelompok pengusaha pengrajin keset yang mereka namai dengan kelompok wanita "Mekar".

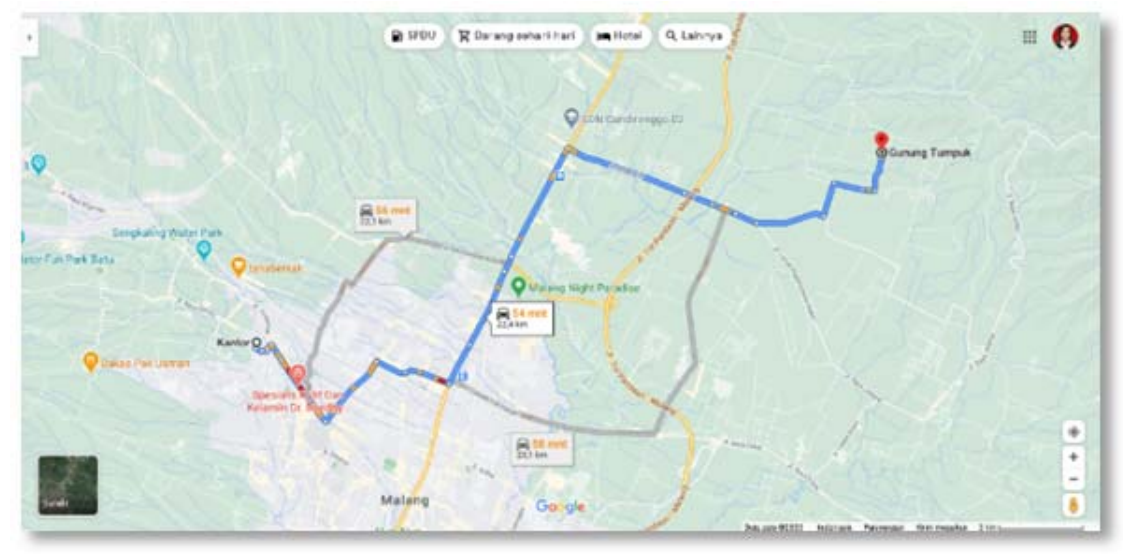

Gambar 2. Peta lokasi kelompok wanita "Mekar"

Kegiatan PKM ini dilakukan dengan metode pelatihan, selanjutnya kelompok wanita "Mekar" dibimbing untuk menerapkan hasil pelatihan tersebut dalam rangka memanfaatkan social media dan platform marketplace dalam memasarkan produk mereka.

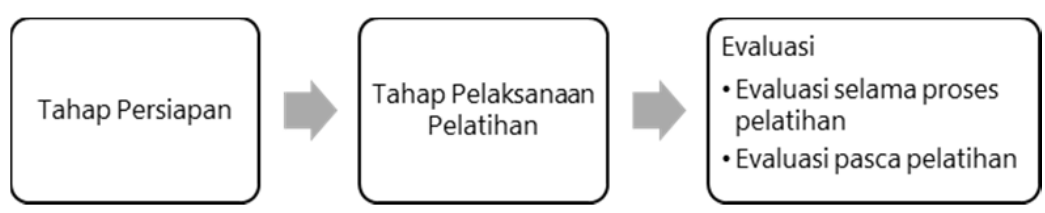

Gambar 3. Tahapan pelaksanaan pelatihan bersama Kelompok Mekar

Berikut adalah tahapan pelatihan yang dilakukan: (1) Tahap Persiapan, dalam tahapan ini dilakukan pendekatan dengan kelompok mekar, melihat apa yang menjadi masalah di kelompok tersebut. Disini juga dilakukan penyusunan materi untuk kegiatan pelatihan; (2) Tahap Pelaksanan Pelatihan, pada 
ABDIMAS: Jurnal Pengabdian Masyarakat Universitas Merdeka Malang

Volume 6, No 1, February 2021: 52-60

tahapan ini dijelaskan tentang pentingnya teknologi dalam meningkatkan produktivitas usaha dan bagaimana memanfaatkan teknologi khususnya internet dalam pemasaran. Selanjutnya sesi pelatihan yang menitikberatkan pada kemampuan membuat akun social media serta akun marketplace dalam hal ini yaitu Instagram, Facebook, Shopee, dan Tokopedia serta cara memaksimalkan penggunaan media tersebut untuk kegiatan pemasaran. Mulai dari teknik pengambilan foto agar menarik, penggunaan hashtag, sistem follow-unfollow untuk menambah follower, sistem gratis ongkir dan bergabung dengan grup usaha sejenis, dll. Pemberian pelatihan ini dilakukan dengan beberapa teknik yaitu: (a) Metode Ceramah, metode ini dipilih untuk memberikan penjelasan mengenai pentingnya teknologi khususnya internet yaitu social media serta akun marketplace dalam hal ini yaitu Instagram, Facebook, Shopee, dan Tokopedia; (b) Metode Tanya Jawab, metode ini sangat penting bagi para peserta pelatihan, baik saat pemberian penjelasan maupun pada saat praktek; (c) Metode Simulasi, metode Simulasi ini pentimg agar pelaku usaha mendapatkan pengalaman langsung. dalam hal ini simulasi yang meraka lakukan adalah membuat akun social media dan marketplace yaitu Instagram, Facebook, Shopee, dan Tokopedia; (4) Evaluasi proses dan hasil dilakukan dengan 2 tahap, yaitu: (a) Evaluasi selama proses pelatihan. Evaluasi pada tahap ini meliputi ketertiban serta kemampuan peserta selama proses pelatihan; (b) Evaluasi pasca pelatihan. Evaluasi pada tahap ini dilihat dari keberhasilan kelompok wanita "Mekar" dalam memanfaatkan internet sebagai sarana pemasaran dan meningkatnya omset penjualan mereka.

\section{HASIL DAN PEMBAHASAN}

Kegiatan ini diikuti oleh ibu-ibu kelompok mekar, yaitu kelompok wanita pengrajin keset kain perca Desa Sidoluhur, Kecamatan Lawang, Kabupaten Malang. Kegiatan ini terdiri dari pelatihan pengembangan pemasaran melalui online marketing yaitu media sosial dan marketplace yang dilaksanakan pada bulan Juli 2020.

\section{Persiapan kegiatan pelatihan}

Persiapan kegiatan pelatihan ini dimulai pada 6 Maret 2020 dengan melaksanakan koordinasi dengan pihak pengrajin keset kelompok wanita "Mekar" untuk memastikan kembali fasilitas maupun perijinan lanjutan yang dibutuhkan untuk mengadakan pelatihan di desa tersebut. Hasil koordinasi yang didapat adalah kegiatan pelatihan akan dilaksanakan di rumah Ibu Usta'ana selaku koordinator kelompok wanita "Mekar" dan segala perlengkapan dan materi disiapkan oleh tim pengabdi. Jumlah peserta yang mengikuti pelatihan ini sebanyak 20 orang.

\section{Pelaksanaan pelatihan}

Pelaksanaan pelatihan dilaksanakan pada bulan Juli 2020. Pelatihan hari pertama diisi dengan penyuluhan tentang apa itu online marketing serta pentingnya online marketing dalam meningkatkan omset penjualan serta pengenalan beberapa media online marketing yakni media sosial yang terdiri 
dari Instagram dan Facebook serta platform marketplace yakni Shopee dan Tokopedia. Dipilihnya media sosial Instagram dikarenakan media sosial ini telah banyak dimanfaatkan oleh pelaku usaha, baik usaha kecil hingga usaha berskala besar (Maharani et al., 2019). Kendala yang dihadapi pada hari pertama ini adalah sebagian besar peserta masih beranggapan bahwa memasarkan produk dengan cara online dirasa lebih sulit dibandingkan dengan mereka harus menawarkan keset mereka ditoko-toko. Kelompok ini harus diberikan pemahaman terlebih dahulu bahwa untuk maju, usaha keset tersebut harus mampu mengikuti permintaan pasar. Pelatihan hari kedua diisi dengan simulasi pembuatan akun social media dan marketplace oleh peserta, kemudian pelatihan bagaimana membuat konten promosi agar menarik minat konsumen, mulai dari pemasangan hashtag, promosi caption dan repost, bebas ongkir Shopee serta teknik mencari follower.

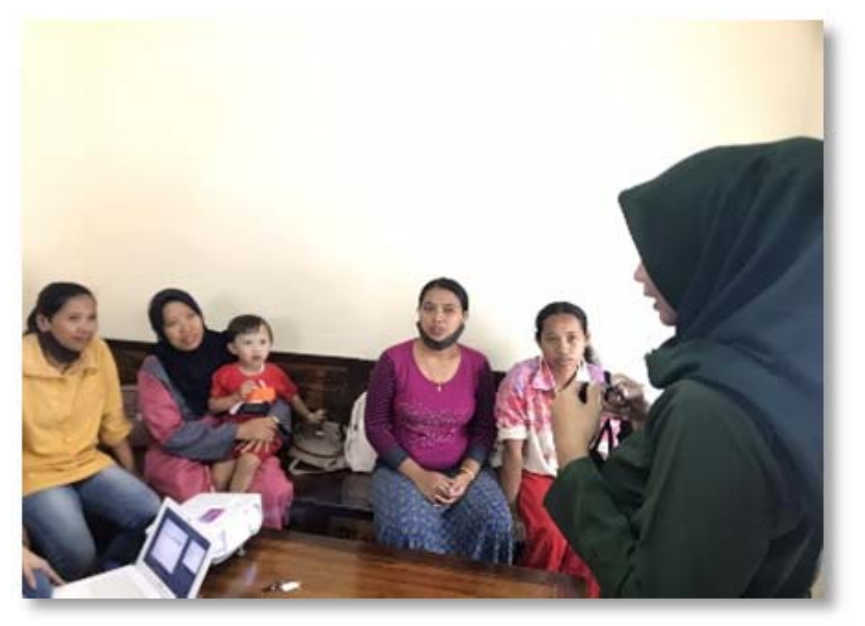

Gambar 4. Pelatihan penggunaan media sosial dan marketplace sebagai media pemasaran online

Pada sesi ini juga diberikan teknik mudah low budget dalam memfoto produk agar terlihat lebih menarik meskipun hanya menggunakan Handphone biasa. kendala yang dihadapi pada hari kedua ini adalah, tidak semua peserta paham dalam mengoprasikan Android, oleh karenanya dipilih beberapa peserta yang dirasa paling cekatan untuk nantinya akan menjadi admin online marketing di kelompok wanita pengrajin keset.

Dari hasil pelatihan penggunaan media sosial dan marketplace sebagai media pemasaran online ini, dihasilkan 4 akun keset mekar yang tersebar di media sosial Facebook dan Instagram, serta marketplace, yaitu Shopee dan Tokopedia. Keempat akun ini yang selanjutnya dikelola oleh bagian pemasaran dari kelompok ini untuk digunakan sebagai media promosi dalam menjualkan produknya secara online. 
ABDIMAS: Jurnal Pengabdian Masyarakat Universitas Merdeka Malang Volume 6, No 1, February 2021: 52-60
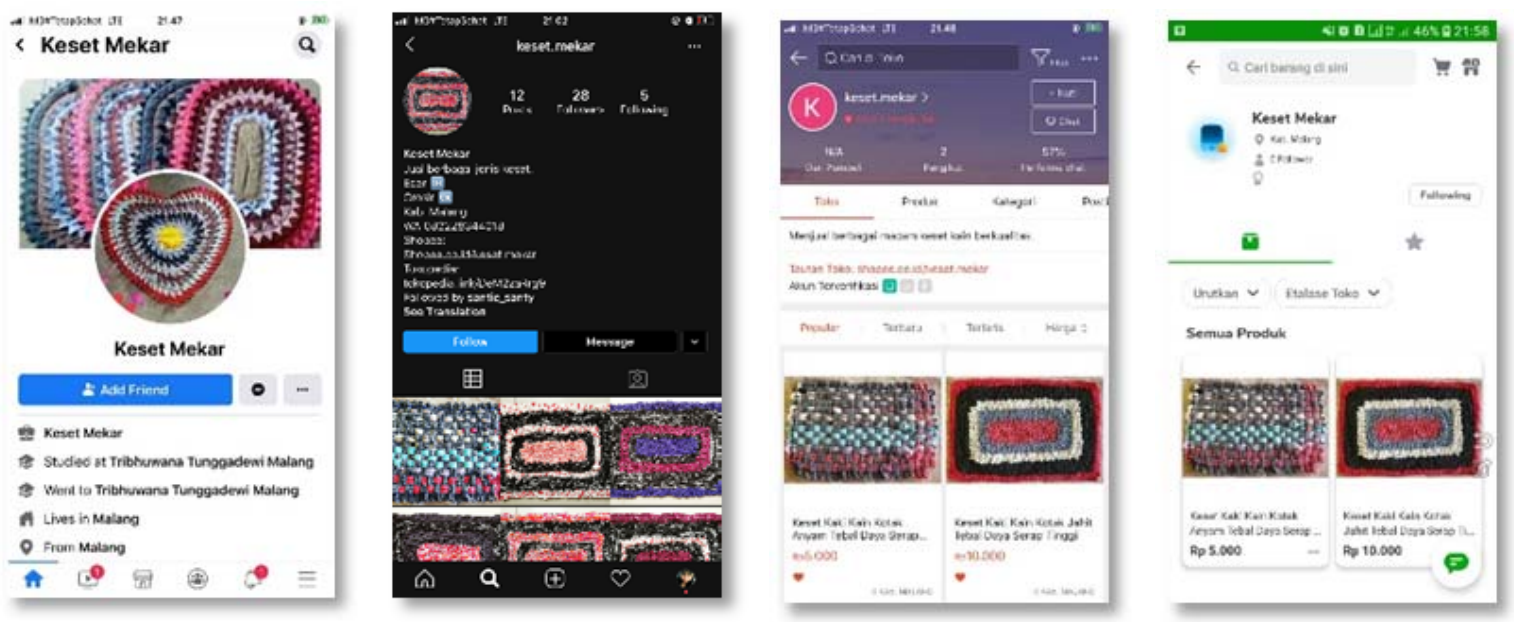

Gambar 5. Akun keset mekar di media sosial Facebook, Instagram, Shopee, Tokopedia

\section{HASIL DAN PEMBAHASAN}

Setelah serangkaian kegiatan pelatihan dan pendampingan dilakukan, foKus kegiatan dipusatkan pada peningkatan omset penjualan keset perca yang dihasilkan oleh Kelompok Mekar. Promosi dilakukan melalui social media Facebook dan Instagram.
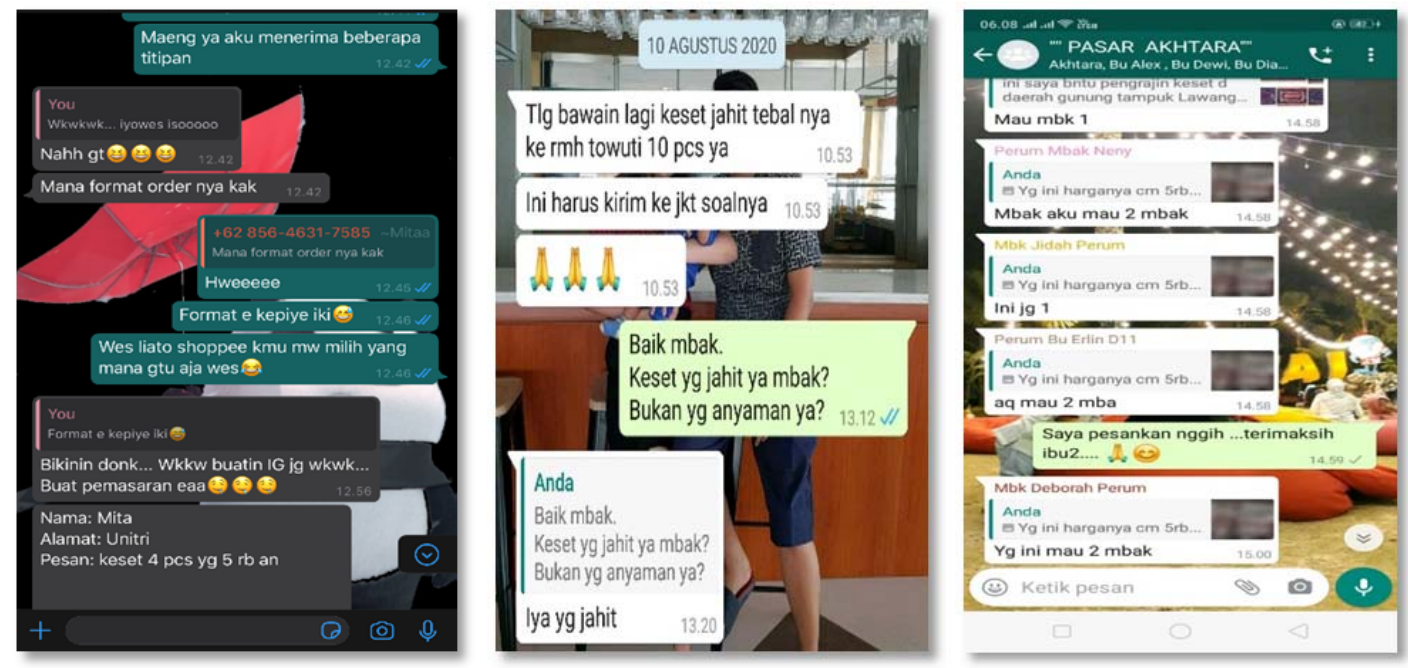

Gambar 6. Beberapa bukti pemesanan keset perca melalui WhatsApp dan WhatsApp Group

Selain melalui marketplace yang telah dibuat, penjualan keset produksi Kelompok Mekar ini juga dilakukan melalui WhatsApp dan WhatsApp Group. Kelompok Mekar tidak hanya melayani konsumen di sekitar Sidoluhur dan Lawang, namun juga telah meluas di sekitar Kota Malang hingga luar Kota. 

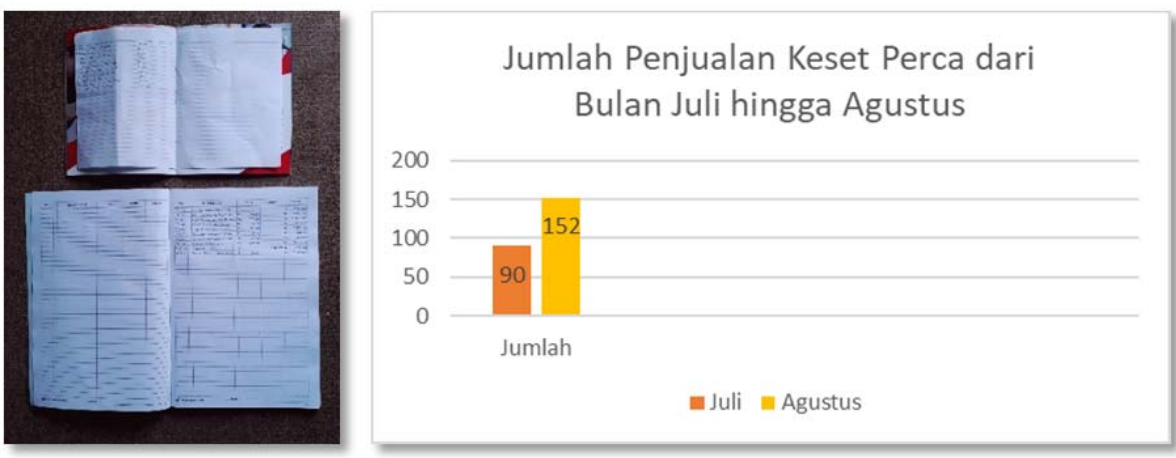

Gambar 7. Buku keuangan pemasukan dan pengeluaran Kelompok "Mekar"

Gambar 8. Grafik peningkatan penjualan keset perca Kelompok Mekar pada Juli-Agustus

Dari buku keuangan Kelompok Mekar, diketahui bahwa penjualan mengalami cukup banyak peningkatan. Peningkatan penjualan mencapai 50\% dimana di bulan sebelumnya penjualan keset Perca sekitar 90 dan meningkat hingga 152 keset perca setelah kelompok wanita "Mekar" ini mendapatkan pelatihan dan pendampingan melalui online marketing. Dari sini dapat diketahui bahwa kegiatan pelatihan dan pendampingan yang telah dilakukan telah membantu Kelompok Mekar dalam mengatasi salah satu masalahnya yaitu masalah pemasaran produk keset percanya.

\section{SIMPULAN DAN SARAN}

\section{Simpulan}

Kegiatan yang diselenggarakan selama bulan Juli 2020 ini telah memberikan beberapa hasil, diantaranya adalah beberapa akun media sosial Facebook dan Instagram, serta beberapa marketplace diantaranya pendaftaran akun di Shopee dan juga Tokopedia. Kegiatan penjualan keset secara online juga dilakukan melalui WhatsApp dan WhatsApp Group. Dari kegiatan pelatihan ini juga telah mampu meningkatkan omset penjualan pengrajin keset kelompok wanita "Mekar" di bulan Agustus hingga 50\%. Kegiatan ini juga telah memnumbuhkan ide-ide kreatif bagi para peserta dalam mmembuat konten pemasaran yang mempunyai daya saing dan foto produk yang mampu menarik minat para konsumen.

\section{Saran}

Kegiatan yang telah diselenggarakan ini cukup membantu masyarakat khususnya pada kelompok wanita "Mekar". Maka dari itu, diharapkan adanya penambahan mitra kerja dalam program ini sehingga semakin banyak kalangan masyarakat yang terbantu untuk memajukan usahanya dan menambah omset dagang.

\section{Ucapan Terima Kasih}

Pengabdi mengucapkan banyak terimakasih kepada Direktorat Riset dan Pengabdian Masyarakat Deputi Bidang Penguatan Riset dan Pengembangan Kementerian Riset dan Teknologi/Badan Riset dan 
ABDIMAS: Jurnal Pengabdian Masyarakat Universitas Merdeka Malang

Volume 6, No 1, February 2021: 52-60

Inovasi Nasional yang telah memberikan dana dalam kegiatan ini, kepada Universitas Tribhuwana Tungga Dewi Malang yang telah memberikan dukungan dari awal hingga terseleksaikannya kegiatan ini, serta kepada Perangkat Desa Sidoluhur dan kelompok wanita pengrajin keset "Mekar" yang telah kooperatif selama kegiatan ini berlangsung.

\section{DAFTAR PUSTAKA}

BPS Kabupaten Malang. (2019). Kabupaten Malang dalam angka 2019. Kabupaten Malang: BPS Kabupaten Malang.

Hadi, A. S., \& Khairi, A. (2020). Pemilihan strategi pemasaran di era digital pada kelompok ibu PKK Desa Gadingharjo. Dinamisia/: Jurnal Pengabdian kepada Masyarakat, 4(1), 127-132. https://doi.org/10.31849/dinamisia.v4i1.3246

Harinie, L. T., Hukom, A., \& Juma'eh, J. (2020). Pendampingan dalam memasarkan produk hasil usaha UKM melalui penggunaan media sosial di Kabupaten Gunung Mas Kalimantan Tengah. Engagement: Jurnal Pengabdian Kepada Masyarakat, 4(1), 51-59.

https://doi.org/10.29062/engagement.v4i1.179

Indrayana, B., Seminar, K. B., \& Sartono, B. (2016). Faktor Penentu Minat Penggunaan Instagram Untuk Pembelian Online Menggunakan Technology Acceptance Model (TAM) dan Theory of Planned Behavior (TPB). Jurnal Aplikasi Bisnis dan Manajemen, 2(2), 138-147.

https://doi.org/10.17358/jabm.2.2.138

Kannan, P. K., \& Li, H. (2017). Digital marketing: A framework, review and research agenda. International Journal of Research in Marketing, 34(1), 22-45. https://doi.org/10.1016/j.ijresmar.2016.11.006

Kaplan, A. M., \& Haenlein, M. (2010). Users of the world, unite! The challenges and opportunities of social media. Business Horizons, 53(1), 59-68. https://doi.org/10.1016/j.bushor.2009.09.003

Maharani, A., Ardiansah, I., \& Pujianto, T. (2019). Efektivitas penggunaan Instagram melalui dua tahap analisis pada Zanana dan Oifyoo. Jurnal Rekayasa Sistem Industri, 8(1), 47-54.

https://doi.org/10.26593/jrsi.v8i1.3216.47-54

Piarna, R., \& Fathurohman, F. (2020). Adopsi E-Commerce oleh konsumen milenial pada produk UMKM di Kota Subang Menggunakan Model UTAUT In Consumer Contex. Jurnal Teknologi Informasi dan Ilmu Komputer, 7(5), 1021. https://doi.org/10.25126/jtiik.2020712635

Rafiah, K. K. (2019). Analisis pengaruh kepuasan pelanggan dan kepercayaan pelanggan terhadap loyalitas pelanggan dalam berbelanja melalui E-commerce di Indonesia. Al Tijarah, 5(1), 4656.

Segarwati, Y., Fitrananda, C., Iqbal, M., \& Rahiem, V. (2020). Pengembangan pemasaran online untuk pelaku usaha di Desa Warnasari, Kecamatan Pangalengan, Kabupaten Bandung. Kaibon Abhinaya: Jurnal Pengabdian Masyarakat, 2(2), 45-52. https://doi.org/http://dx.doi.org/10.30656/ka.v2i2.2066

Suyanto, M. (2007). Marketing strategy top brand Indonesia. Yogyakarta: ANDI.

Widiana, M. E., Supit, H., \& Hartini, S. (2012). Penggunaan teknologi internet dalam sistem penjualan online untuk meningkatkan kepuasan dan pembelian berulang produk batik pada Usaha Kecil dan Menengah di Jawa Timur. Jurnal Manajemen dan Kewirausahaan, 14(1), 71-81.

https://doi.org/10.9744/jmk.14.1.72-82 